\title{
Newspaper Coverage of Sexual Assaults in South Korea: Before and after \#MeToo Movement
}

\author{
Jooyeon Lee \\ Macau University of Science and Technology
}

\begin{abstract}
This study explores differences in South Korean newspaper coverage related to cases of sexual assault on females before and after the \#MeToo movement. To this end, a content analysis was conducted to examine the framing of newspaper coverage of sexual assault by politicians in 2014 and 2018. In total, 755 news stories were analysed, revealing 10 times increase in the number of articles dealing with sexual violence cases after the \#MeToo movement. In addition, it was found that the number of newspaper articles representing the voices of women who were victims of sexual assault or representing the position of women's organizations calling for social change and the protection of women's rights increased significantly after the \#MeToo movement. In particular, a significant increase in newspaper coverage discussing problems with the legal system and calling for an urgent improvement to its dealings with sexual assault cases was found. Despite the \#MeToo movement, however, the examined newspaper coverage still used an episodic frame more often than a thematic one in dealing with sexual violence against women and the articles still contained many provocative words, such as 'adultery' and 'infidelity', aimed at arousing readers' curiosity and interest.
\end{abstract}

Keywords: Sexual assault, framing analysis, Newspaper coverage, \#MeToo

\section{Introduction}

In South Korea, the \#MeToo movement was set in motion when female prosecutor Seo Ji-hyun made an appearance on JTBC evening live news on Jan. 29, 2018 to expose the sexual harassment she suffered inside the prosecution agency eight years previous. Her courageous accusation made a considerable impact on Korean society (Hasunuma \& Shin, 2019). At the time, although a patriarchal culture had been maintained for a long time, it was also believed that women's increased enthusiasm for education was gradually expanding the channels and rights by which women could enter society. Seo's revelation, however, clearly demonstrated that Korean society was still unable to escape the sexist social structure that forced and silenced the sacrifices of women, who remain the main victims in cases of sexual violence. Since then, sexual assault cases in which the perpetrator is of significant fame, social status, or power have been spotlighted by the media (Jeong, 2018).

Many scholars argue that crimes such as sexual assault are often indirectly experienced through the media rather than through direct experience (Kim et al., 2013; Kim \& Jang 2011; Lee et al., 2009). Given that this is the case, media coverage can have a significant effect. Because it is rare for the public to experience criminal events on their own, the information received from the press can instil a right or a wrong perception of that particular crime (Hindes \& Fileborn, 2019; Hust et al., 2014).

The press does not simply emphasise specific issues. Rather, it partakes in agenda-setting and priming by communicating a meaning and interpretation of realities. This is done by describing, explaining and diagnosing specific issues and suggesting measures to be taken with respect to them. Therefore, from news coverage, receivers learn not only what issues are important but also 'what' the issues are and about and the detailed contents of the 'what'. In news, a frame is a style by which the meaning of a specific event or issue is formed when the media constructs a reality. 
In this vein, the present study seeks to examine cases of sexual violence as one among many criminal issues that can be indirectly experienced through the media. Scholars who have studied media and gender issues mention that the number of women who appear in television news is significantly smaller than that of men and that Korea's patriarchal culture has portrayed men as superior to women while portraying women as subordinate or marginalised (Kim, 2004). Given this reality, the \#MeToo movement, which spread in 2018, is believed to have provided an important opportunity for women to give rise to change in the social perceptions in Korean society. In particular, they can do so by publicly mentioning cases of sexual violence that they had hidden or been forced to remain silent on as a way of directly voicing their rights.

According to research on the effect of news frames, people's interpretation of and opinions on the content of news may differ depending on the position or report style of the press. In other words, entirely different news stories can be constructed for the same event depending on the journalist's view, the setting of major figures and the nature of the of storytelling. When conveying complex realities through news, the press can present the same news in different ways according to the context and viewpoint, and accordingly, the news frame can be altered. Given this, this study will compare and analyse the sexual assault articles that appeared in The Hankyoreh, a relatively progressive newspaper, with those in JoongAng Ilbo, one of Korea's leading conservative newspapers. Overall, the main purpose of this study is to discover whether the behaviour of the Korean media changed after the \#MeToo movement with respect to its reports on sexual violence. In this vein, the nature of newspaper reports on the sexual assault perpetrated by former National Assembly Speaker Park Hee-tae, who was exposed prior to the \#MeToo movement, are examined and compared with reports on the sexual assault perpetrated by the former governor of North Chungcheong Province, Ahn Hee-jung, who was exposed after the \#MeToo movement.

\section{Literature reviews}

\section{News frame}

Framing effect theory can explain in detail the effects of news story composition, or how the composition of a news story influences its receivers (Kosicki, 1993; Price et al., 1997). In addition, framing effect theory emphasises that the awareness of causes of or changes in public opinion are not determined only by how the press deals with specific issues but are also influenced by how it composes the detailed contents and outlines of the issues it presents.

The concept of frame can be divided into news frame and individual frame (Scheufele, 1999). An individual frame is a set of guidelines for information processing, however, a news frame is a key idea or outline that gives meaning to an event and is 'an attribute of the news itself' (Entman, 1991:7).

The classical concept of frame was developed by Goffman (1974) under the influence of Schutz's phenomenology. Before discussing the concept, he points out that there is a unique way of giving a meaning to social organizations, which he conceptualises in the term framework. Goffman defines a framework as an outline of an interpretation of daily life through which individuals can manipulate their frame, while he defines frame as an outline that enables people to identify events or life experiences, reconfirm them and classify them. That is, Goffman's 'frame' refers to a frame of interpretation, a schema or a viewpoint.

Since the concept of news frame was used by Tuchman (1978) and Gitlin (1980), it has influenced many researchers, including Entman (1991). Entman defines frame by refining the concept of news frame used by Tuchman and Gitlin. He argues that the essence of a news frame is ultimately to zoom in or out on only one aspect of the described reality, that is, to emphasize certain aspects of reality. He also maintains that the effect of news framing is not limited to an adjustment of scale but is also found in the discourse area that establishes the meaning of news. He explains the conceptual definition of frame by dividing it into the following parts: (1) 
chosen/emphasised aspects; (2) problem definition (determination); (3) causes/motives; (4) evaluation; and (5) proposal of solutions. Entman's interpretation adopts the basic assumptions made about news frames by Tuchman and Gitlin (ideological reality construction, institutionalised practices in the news editing process, etc.), but provides the tools for a more refined analysis of the importance and themes of news stories.

As an example, Entman makes a comparative analysis of U.S. news coverage of a Korean Air airliner being shot down by a fighter of the former Soviet Union with that of an Iranian passenger airplane being shot down by the U.S. According to Entman, the two basically similar events (in which a passenger airplane was shot down) were framed discriminately. That is, while the U.S. press framed the shooting down of the Korean Air airliner as 'immoral violence' on the part of the former Soviet Union, it used a passive expression to describe the shooting down of the Iranian passenger airplane, emphasizing 'an error in technical operation'. In this way, the U.S. press used a self-centred frame of interpretation.

Gamson \& Modigliani (1989) share the assumption that realities provided by the media are constructed realities but attempt a more methodological approach to the issue. Focusing on issue culture, the authors explain that while an issue occurs, develops and declines, a news frame is a view centring on theme construction necessary for knowing what the issue is about and how to understand it. They further emphasise the importance of issue culture and claim that a news frame puts forward a set of interpretive semantic elements for understanding the issue culture of a society. What matters in the issue culture of a society is the direction of public opinions on a specific issue, and it is a set of interpretive semantic elements that provide decisive contextual information that help in understanding the intended direction. The news frame is thus the core that provides the meanings of the elements.

Lastly, Iyengar et al. (1982) insists that the concept of frame refers to a subtle change in the suggestion or statement of a problem and claims that socio-political news can be divided into that with an episodic frame and that with a thematic frame. According to him, news with an episodic frame describes an issue as an individualised personal or group problem and is focused on symptomatic events, which are revealed as results of the issue. On the contrary, news with a thematic frame provides information necessary for understanding the causes and background of a social problem and helps in the consideration of realities from a more structured viewpoint.

The framing effect as explained by Iyengar implies that when a news text begins with presenting a frame for a specific social problem, it increases the accessibility to related concepts and influences judgment on who is responsible for the problem. That is, news viewers exposed to an episodic frame perceive a specific social problem not as a problem of social structure but as a problem of an individual's behaviour or character. This further implies that discovering who should be responsible or punished for a social problem is also a matter individual behaviour and character.

\section{The \#MeToo movement in South Korea and the researches of news coverage of sexual assaults}

The \#MeToo movement began in 2006 when Tarana Burke, a victim of sexual violence and now a civil rights activist, used the term \#MeToo on social media to help women revive their authority by sympathizing with one another rather than remaining silent about the sexual violence they had been subject to (Frye, 2018). Years later, after Harvey Weinstein's 2017 sex abuse case had drawn the world's attention, American actress Alyssa Milano wrote on her Twitter account, "If you've been sexually harassed or assaulted write "me too" as a reply to this tweet', thus instigating the \#MeToo movement in earnest (Flum, 2018).

In South Korea, the \#MeToo movement began in January 2018 when a female prosecutor began to expose the sexual harassment she had experienced directly inside the prosecution agency. The victim, Seo Ji-hyun, revealed on a live news broadcast the sexual harassment she had received eight years previous from Ahn Tae-geun, her 
senior prosecutor. Prosecutor Seo Ji-hyun mentioned the issue of corruption within the prosecution agency as an example of the unjustified personal appointment she received after the sexual harassment case. In bringing her sexual harassment case inside the prosecution to light, Seo Ji-hyun declared that she wanted to disclose her story to the public and send a message to all Korean women affected by sexual abuse that the abuse was not their fault. Seo's case of sexual harassment within the prosecution agency was enough to draw the attention of Korean society due to her social status as well as the publicity she received through the media (Hasunuma \& Shin, 2019).

Since the \#MeToo movement began, sexual assault cases against politicians and celebrities with strong influence have been continuously reported by the media. Unlike general crimes, these revelations have led to strong criticism of the perpetrators' honour and moral character in a Korean society in which moral character is highly valued (Jeong, 2018). This strong public rebuke actually caused public backlash against the \#MeToo movement when male actor Cho Min-ki had difficulty handling his sexual harassment case and eventually committed suicide (Ryall, 2018). In addition, a series of celebrity sexual assault accusations that have been later discovered to be misalleged have dimmed the original intention of the early \#MeToo movement, which was to work together in sympathy with women who had been damaged, and created a mood of misogyny beyond the general gender confrontation between men and women.

In her research discussing the present and future of the \#MeToo movement, Kim (2018) makes an argument with regard to why the \#MeToo movement spread quickly to Korean society. In particular, Kim points out that the \#MeToo movement is a movement in which a clear sense of purpose was expressed, namely, to trust women's narratives, sympathise with their suffering and resolve the issue together. Kim also claims that the rapid spread of the \#MeToo movement was due to the fact that, unlike other feminist movements that require their participants to take on a feminist identity, the \#MeToo movement made it possible to empathise with the story of victimised women. In other words, the movement actively informed the public of the damage women had incurred and engaged them with the common purpose of promoting social change.

There is no doubt that public interest in violence against women has been significantly increased since the \#MeToo movement began, but it is true that studies of violence against women, especially sexual violence, rape, sexual harassment, and so on, have not been very actively investigated. Thus most studies of sex crimes against women, in particular, focus on how the media reported sexual crimes. As a the typical study, Hong (2009) studied the descriptions of sexual violence produced by Korean newspapers through a framing analysis of newspaper articles related to sexual assaults and she confirmed that Korean society still adhered to a patriarchal mindset according to which women must maintain purity in their bodies. She also noted that this patriarchal mindset still resulted in the passing of blame to victims of sexual violence in newspaper coverage related to sexual assaults.

As another study that analysed the newspaper reports of sexual assault, Kim \& Jang (2011) analysed 683 newspaper articles excerpted from a total of three newspapers to investigate the nature of newspaper coverage of sexual assault cases in Korea in 2009. They noted that most articles were written in a straight style, focusing on simple information or fact delivery rather than structural social problems or measures for eradicating sexual assaults. Articles that elicited deep future-oriented discussions on how to change gender perceptions in a malecentred Korean society were found to be rare, meaning that Korean newspapers were conservative in their reports on gender issues.

While the abovementioned studies have focused on identifying the superficial characteristics of newspaper articles on incidents of sexual assault, however, Kim et al. (2013) conducted experimental studies to discover which of the three frequently used frames (victim frame, law/system frame, perpetrator frame) actually had more influence on people's perceptions. In their experiments with 175 college students, it was found that the perpetrator frame and the law/institutional frame had the most significant influence on the perception of the 
participants. The authors also pointed out that the reports that attribute incidents of sexual violence to the situational factors of the victims of the violence might lead to more empathy than those that frame the victimised individuals as personal victims.

\section{Research questions}

This research focuses on analysing the sexual harassment case of the former National Assembly Speaker Park Hee-tae before the \#MeToo movement broke out and the sexual assault case of former National Assembly member Ahn Hee-jung after the \#MeToo movement broke out.

Research Question 1: What type of frame is mainly presented in the newspaper coverage of sexual assault? Are there changes in the use of such frames between newspapers before and after the \#MeToo movement?

Research Question 2: Is an approach focused on equality used in reporting sexual violence? Is there any change in the use of this approach between newspapers before and after the \#MeToo movement?

Research Question 3: What are the main topics presented in newspaper coverage of sexual assault? Is there a change in the use of these topics between newspapers before and after the \#MeToo movement?

\section{Methods}

This study aims to investigate the differences in newspaper reports related to female sexual assault cases in politics before and after the \#MeToo movement in Korea. To achieve the purpose of this research, two newspapers, The Hankyoreh and JoongAng Ilbo, were selected based on their political ideologies.

The Hankyoreh has established itself as one of Korea's leading progressive newspapers and has a relatively young readership compared with Korea's other major newspapers. In particular, The Hankyoreh expresses the viewpoints of centre-leftists and reports with relatively high interest on a number of progressive issues, such as environmentalism and feminism (Kim, 2011). The Hankyoreh, which appeared in the 1980s, has a relatively solid readership, although it does not have a long history compared with many of Korea's conservative newspapers. JoongAng Ilbo is one of Korea's leading conservative newspapers and, unlike liberal newspapers, it expresses interest in nationalism and national security. Along with two other leading conservative newspapers, Chosun Ilbo and Dong-A Ilbo, it holds more than $75 \%-80 \%$ percent of the nation's total subscribers (Kim, 2002). According to a recent report issued by the Korea Audit Bureau of Certification in 2019, JoongAng Ilbo was ranked third and The Hankyoreh was ranked eighth among 172 Korean newspapers. Among major daily newspapers, JoongAng Ilbo was ranked third, and The Hankyoreh was fourth.

The newspaper articles analysed in this study were extracted through BigKinds (https://www.bigkinds.or.kr/), a Korean news big data analysis system. 'Sexual violence' and 'sexual harassment' were used as search terms to extract articles reported in The Hankyoreh and JoongAng Ilbo on the sexual assault cases of the two previously mentioned politicians. Among the extracted articles, those with no direct link to sexual harassment/assault cases and those in which the sexual harassment/assault cases were not explained were excluded from the study. Accordingly, 58 reports were found on the sexual harassment by Park Hee-tae (before the \#MeToo movement), while 697 articles were found related to Ahn Hee-jung's sexual assault (during and after \#MeToo movement; Table 1). 
Table 1 Period of analysis and the number of analysed newspaper articles

\begin{tabular}{lll}
\hline \#MeToo movement & Period of analysis & $\begin{array}{l}\text { Number of newspaper } \\
\text { articles }\end{array}$ \\
\hline $\begin{array}{l}\text { Before } \\
\text { (Park Hee-tae's sexual } \\
\text { harassment) }\end{array}$ & $\begin{array}{l}1^{\text {st }} \text { of September, 2014- } \\
28^{\text {th }} \text { of April, 2017 }\end{array}$ & 58 \\
\hline $\begin{array}{l}\text { After (Ahn Hee-Jung's } \\
\text { sexual assaults) }\end{array}$ & $\begin{array}{l}5^{\text {th }} \text { of March, 2018-3 } \\
\text { May, 2019 }\end{array}$ & 697 \\
\hline
\end{tabular}

In this study, a quantitative content analysis was conducted to analyse the frames of the news articles related to the abovementioned sexual assaults. To analyse the type of frame, the articles were divided into those with a thematic frame and those with an episodic frame, as suggested by Iyengar \& Simon (1993). News with a thematic frame, as explained earlier in the literature study, delves into issues and events through their social structure or historical background. For the present purposes, this thus refers to articles that include an in-depth diagnosis of the causes of and provides alternative viewpoints on sexual assault in various social and structural contexts. In contrast, news with an episodic frame presents a dramatic screen through specific cases and on-site interviews or highlights visual elements and descriptive aspects of the reported events. In other words, articles with an episodic frame list fragmentary facts about individual events and highlight the deviance of these events rather than linking them to social structures. In addition, a mixed frame (episodic and thematic) category was added for newspaper articles that adhered to the characteristics of both these frames.

Several previous studies on the performance of the media suggest that women have been devalued by the news. Given that the \#MeToo movement began with the intention of reviving women's authority by allowing women empathise with one another instead of remaining silent about the damage they had received, an analysis of nomenclature was added to this study to determine whether the media has evaluated men and women equally in articles on the \#MeToo movement. It was adopted from Andelsman \& Mitchelstein's research (2019) and the concept of equality approach was modified to apply to Korea case. An analysis of the frame of articles related to the abovementioned sexual assaults, as well as of the topics and characteristics emphasised in these reports, was also undertaken. Further, given the strong influence of the \#MeToo movement in Korean society, the coding scheme used in Kim \& Jang's study (2011) was added to see if Korean newspapers that reported on sexual violence in a conservative manner showed any changes. The main items of analysis that were used in this study are as follows:

- Newspaper types: straight news report, brief news report, background news report, editorial, opinion column, feature, interview or Q\&A, statistic report.

- News frame types: thematic frame, episodic frame, thematic and episodic (mixed) frame.

- Article approaches: equality approach, inequality approach

- The specific topics of news frame: (1) general information on sexual assaults (including articles about the trial progress and proceedings); (2) background of sexual assaults (including sexual abuse by the power of the vocational authority and threats or promises of advancement tied to sexual favours); (3) victimization and blaming of the victim; (4) the influence of the \#MeToo movement; (5) judicial judgment and legal system issues; (6) adultery/affairs; (7) secondary assault; (8) perjury/lying; (9) the response of the government or political circles; (10) the responses of women and social groups; (11) public opinion; (12) the perpetrator's strategy or response; (13) the perpetrator's political image or morality; (14) The impact on the perpetrator and the perpetrator's psychological state; (15) the victim's 
strategy or response; (16) the impact on the victim and the victim's psychological state; (17) the impact of the events on society; and (18) foreign media coverage.

- Characteristics highlighted by the article: (1) the victim; (2) the perpetrator; (3) problems with the law/system and its need to be supplemented; (4) overall problems in society; and 5) incident/accident information.

Content analyses were carried out based on the above coding scheme, for which two coders, including the researchers, were employed. The coders were involved in the overall process, from extracting articles to organizing coding checks to be used in the analysis. The intercoder reliability between the coders was measured using the ReCAL2 website (Freelon, 2010). The intercoder reliability for frame types (thematic vs. episodic) was found to be $97.9 \%$, with a Cohen's Kappa coefficient of 0.958 . For approach (equality vs. inequality), the intercoder reliability was $98.4 \%$, with a Cohen's Kappa coefficient of 0.96 . For the main topics of newspaper coverage, the intercoder reliability was $91.9 \%$, with a Cohen's Kappa coefficient of 0.909 .

\section{Findings}

A total of 755 newspaper articles dealing with sexual violence cases in political circles before and after the \#MeToo Movement were analysed. JoongAng Ilbo generated a greater number of articles overall, amounting to $491(65 \%)$ in total, while The Hankyoreh reported 264 relevant articles (35\%). With respect to the types of articles, spotlight news reports accounted for the highest ratio (65.2\%), followed by background news reports (20.8\%) and then opinion columns (5.2\%). Some changes before and after the beginning of the \#MeToo movement were revealed, especially in the ratio of background news reports, which was $10.3 \%$ before the \#MeToo movement and $21.7 \%$ after the movement. Background news reports are articles that provide background information on the verdict before the perpetrator is convicted by the court. Therefore, this change can be interpreted as being due to the fact that the public's attention became more focused on judicial decisions in sexual assault cases as the \#MeToo movement became more active.

The first research question in this study was with respect to what type of frame sexual violence articles have mainly used. As shown in Table 1 below, newspaper articles on sexual violence were found to use mainly episodic frames rather than subject-oriented one. The results also revealed little difference between the two newspapers, which differ in their political personalities, as well as that there was little significant change in either after the \#MeToo movement. These results appear to confirm that, as noted in several other studies analysing past reports of sexual assault, Korean newspapers are more focused on articles that stimulate readers' interest by simply describing sex crimes rather than engaging them in in-depth discussions, especially when women are the victims. However, it was found that since the beginning of the \#MeToo movement the mixed theme-oriented frame and episodic frame have become more popular, this being represented by a slight increase in the number of articles written with these frames. (Table 2; 13.8\% before the \#MeToo movement and 22.5\% after the movement).

Table 2 The different types of frame (Thematic vs. Episodic)

\begin{tabular}{lllll}
\hline \#MeToo & Newspaper & Thematic Frame & Episodic Frame & Thematic+Episodic \\
\hline \multirow{3}{*}{ Before* } & JoongAng Ilbo & $1(8.3 \%)$ & $8(66.7 \%)$ & $3(25 \%)$ \\
\cline { 2 - 5 } & The Hankyoreh & $10(21.7 \%)$ & $31(67.4 \%)$ & $5(10.9 \%)$ \\
\cline { 2 - 5 } & Total & $11(19 \%)$ & $39(67 \%)$ & $8(13.8 \%)$ \\
\hline \multirow{2}{*}{ After** } & JoongAng Ilbo & $39(8.1 \%)$ & $341(71.2 \%)$ & $99(20.7 \%)$ \\
\cline { 2 - 5 } & The Hankyoreh & $36(16.5 \%)$ & $124(56.9 \%)$ & $58(26.6 \%)$ \\
\cline { 2 - 5 } & Total & $75(10.8 \%)$ & $465(66.7 \%)$ & $157(22.5 \%)$ \\
\hline $2=2.280, \mathrm{p}<0.001, \mathrm{df}=2, * * \chi 2=16.701, \mathrm{p}<0.001, \mathrm{df}=2$ & &
\end{tabular}


The second question investigated was with regard to whether the articles covering sexual violence put men and women on an equal footing or whether they clearly emphasised an inequality between men and women in describing stories of male perpetrators and female victims. The results shown below in Table 3 indicate that most articles did not portray perpetrators and victims on an equal footing and that there was little difference in this respect after the \#MeToo movement. The Hankyoreh (38.1\%), however, did described the male perpetrator and the female victim on a more equal footing compared with JoongAng Ilbo (21.9\%).

Table 3 The frame approach (equality vs. inequality)

\begin{tabular}{llll}
\hline \#MeToo & Newspaper & Equality approach & Inequality approach \\
\hline \multirow{3}{*}{ Before* } & JoongAng Ilbo & $3(25 \%)$ & $9(75 \%)$ \\
\cline { 2 - 4 } & The Hankyoreh & $11(23.9 \%)$ & $35(76.1 \%)$ \\
\cline { 2 - 4 } & Total & $14(24.1 \%)$ & $44(75.9 \%)$ \\
\hline \multirow{2}{*}{ After** } & JoongAng Ilbo & $105(21.9 \%)$ & $374(78.1 \%)$ \\
\cline { 2 - 4 } & The Hankyoreh & $83(38.1 \%)$ & $135(61.9 \%)$ \\
\cline { 2 - 4 } & Total & $188(27 \%)$ & $509(73 \%)$ \\
\hline $2=0.938, \mathrm{p}>0.05, \mathrm{df}=1, * * \chi 2=19.845, \mathrm{p}<0.001, \mathrm{df}=1$
\end{tabular}

In addition, this study examined which frames the sexual assault-related articles emphasised, and investigated whether the Korean newspapers' conservative reporting behaviour, such as interpreting a case from a maledominated perspective changed in the wake of the \#MeToo movement. As can be seen in Table 4, it was found that there were a number of news articles highlighting the viewpoints of the victims after the beginning of the \#MeToo movement. As there were no news articles highlighting or mentioning the aspects of victims before the \#MeToo movement, the number of news articles describing the positions of female victims or mentioning their influence on Korean society has increased significantly since the \#MeToo movement began. This result is evidence of the \#MeToo movement's strong influence on Korean society. In the straight news reports, however, which provide only general information about sexual assaults cases, accounting for $25.7 \%$ as can be shown in table 4 below, Korean newspapers have maintained a male-dominated conservative attitude in sexual assaults articles as claimed by Kim \& Jang' research (2011).

Table 4 The characteristics emphasised by newspaper coverage

\begin{tabular}{|c|c|c|c|c|c|c|c|}
\hline \#MеTоo & Newspaper & Victim & $\begin{array}{l}\text { Perpet- } \\
\text { rator }\end{array}$ & $\begin{array}{l}\text { Legal } \\
\text { system }\end{array}$ & $\begin{array}{l}\text { Social } \\
\text { issue }\end{array}$ & $\begin{array}{l}\text { Infor- } \\
\text { mation }\end{array}$ & $\begin{array}{l}\text { Press } \\
\text { releases }\end{array}$ \\
\hline \multirow{3}{*}{ Before* } & JoongAng Ilbo & - & $\begin{array}{l}2 \\
(16.7 \%)\end{array}$ & $\begin{array}{l}2 \\
(16.7 \%)\end{array}$ & $\begin{array}{l}1 \\
(8.3 \%)\end{array}$ & $\begin{array}{l}2 \\
(16.7 \%)\end{array}$ & $\begin{array}{l}5 \\
(41.7 \%)\end{array}$ \\
\hline & $\begin{array}{l}\text { The } \\
\text { Hankyoreh }\end{array}$ & - & $\begin{array}{l}1 \\
(2.2 \%)\end{array}$ & $\begin{array}{l}20 \\
(43.5 \%)\end{array}$ & $\begin{array}{l}5 \\
(10.9 \%)\end{array}$ & $\begin{array}{l}20 \\
(43.5 \%)\end{array}$ & - \\
\hline & Total & - & $\begin{array}{l}3 \\
(5.2 \%)\end{array}$ & $\begin{array}{l}22 \\
(37.9 \%)\end{array}$ & $\begin{array}{l}6 \\
(10.3 \%)\end{array}$ & $\begin{array}{l}22 \\
(37.9 \%)\end{array}$ & $\begin{array}{l}5 \\
(8.6 \%)\end{array}$ \\
\hline \multirow{3}{*}{ After** } & JoongAng Ilbo & $\begin{array}{l}94 \\
(19.6 \%)\end{array}$ & $\begin{array}{l}77 \\
(16.1 \%)\end{array}$ & $\begin{array}{l}61 \\
(12.7 \%)\end{array}$ & $\begin{array}{l}46 \\
(9.6 \%)\end{array}$ & $\begin{array}{l}127 \\
(26.5 \%)\end{array}$ & $\begin{array}{l}74 \\
(15.4 \%)\end{array}$ \\
\hline & $\begin{array}{l}\text { The } \\
\text { Hankyoreh }\end{array}$ & $\begin{array}{l}40 \\
(18.3 \%)\end{array}$ & $\begin{array}{l}17 \\
(7.8 \%)\end{array}$ & $\begin{array}{l}47 \\
(21.6 \%)\end{array}$ & $\begin{array}{l}38 \\
(17.4 \%)\end{array}$ & $\begin{array}{l}52 \\
(23.9 \%)\end{array}$ & $\begin{array}{l}24 \\
(11 \%)\end{array}$ \\
\hline & Total & $\begin{array}{l}134 \\
(19.2 \%)\end{array}$ & $\begin{array}{l}94 \\
(13.5 \%)\end{array}$ & $\begin{array}{l}108 \\
(15.5 \%)\end{array}$ & $\begin{array}{l}84 \\
(12.1 \%)\end{array}$ & $\begin{array}{l}179 \\
(25.7 \%)\end{array}$ & $\begin{array}{l}98 \\
(14.1)\end{array}$ \\
\hline
\end{tabular}

${ }^{*} \chi^{2}=26.698, \mathrm{p}<0.001, \mathrm{df}=4,{ }^{* *} \chi 2=25.397, \mathrm{p}<0.001, \mathrm{df}=5$ 
It was finally investigated which specific topics were intensively dealt with in news reports on sexual violence and whether there were differences in this respect before and after the \#MeToo movement. Table 5 shows that quite a few articles pointed out the problems of the current legal system both before and after the \#MeToo movement. Of the articles dealing with Park Hee-tae's sexual harassment case, which occurred before the \#MeToo movement, a large percentage dealt with the political and government response to the sexual harassment, further taking into account the political power and influence of the then-Republican perpetrator. However, the Ahn Hee-jung sexual assault case, which took place after the beginning of the \#MeToo movement, produced a large number of articles (24.7\%) about problems with the current legal system as well as the legal sentences the perpetrators might face, an indirect indication that the \#MeToo movement has changed people's perception of violence against women. Women may have been more inclined to hide or remain silent on sexual crimes in the past, whereas after the \#MeToo movement, women are willing to actively share the facts of their suffering, in part due to the fact that the public's interest in the current legal system has increased. In particular, the fact that newspaper reports have made many reports on the problems of the current legal system with regard to sexual violence proves that the public's interest has increased.

Table 5 The main themes of sexual assault news in Korea*

\begin{tabular}{lll}
\hline Topics & Before \#MeToo & After \#MeToo \\
\hline General information on sexual assaults & $10(17.2 \%)$ & $91(13.1 \%)$ \\
\hline Background of sexual assaults & $5(8.6 \%)$ & $41(5.9 \%)$ \\
\hline Victimization and blaming the victim & $1(1.7 \%)$ & $19(2.7 \%)$ \\
\hline The influence of the \#MeToo movement & - & $31(4.4 \%)$ \\
\hline Judicial judgment and legal system issues & $11(19 \%)$ & $172(24.7 \%)$ \\
\hline Adultery/affairs & - & $6(0.9 \%)$ \\
\hline Secondary assault & - & $30(4.3 \%)$ \\
\hline Perjury/lying & $1(1.7 \%)$ & $4(0.6 \%)$ \\
\hline The responses of the government and political circles & $19(32.8 \%)$ & $93(13.3 \%)$ \\
\hline The response of women and social groups & - & $18(2.6 \%)$ \\
\hline Public opinion & $3(5.2 \%)$ & $15(2.2 \%)$ \\
\hline Perpetrator's strategy/response & - & $51(7.3 \%)$ \\
\hline Perpetrator's political image and morality & $4(6.9 \%)$ & $43(6.2 \%)$ \\
\hline The impact on and psychological state of the perpetrator & $2(3.4 \%)$ & $10(1.4 \%)$ \\
\hline The victim's strategy/response & - & $40(5.7 \%)$ \\
\hline The impact on and psychological state of the victim & - & $23(3.3 \%)$ \\
\hline The impact of the events on society & $2(3.4 \%)$ & $4(0.6 \%)$ \\
\hline Foreign media coverage & - & $6(0.9 \%)$ \\
\hline$* 2=43.046, p<0.001$, df $=17$ & & \\
\hline
\end{tabular}

\section{Conclusion and discussion}

The main purpose of this study was to determine whether the recent \#MeToo movement affected Korea with respect to the reporting behaviour of Korean newspapers in sex crime articles. The selection of newspaper coverage related to sexual assaults to be analysed in this study was based on the date of January 2018, when the \#MeToo movement began in Korea. In this study, two newspapers with different political orientations were also chosen, considering that the same event could have a different influence on readers depending on how the related news story was presented. The Hankyoreh, which has a progressive tendency, and Joongang Ilbo, 
Korea's leading conservative newspaper, were selected and compared. Overall, a total of 755 articles on sexual violence were analysed.

In this study, it was found that the \#MeToo movement had a considerable impact on Korean society, but that newspaper reports on sexual violence still only convey fragmentary and superficial information. In particular, straight news reports remained the most frequently used type of report after the \#MeToo movement. It was also found that episodic frames were used more often than thematic frames. These results reveal that Korean newspapers have failed to produce balanced articles containing in-depth discussions on the enhancement of women's rights, which should be undertaken in conjunction with the provision of basic information on the sexual violence in these cases.

Unlike in the past when sexual violence was considered only as a problem for only the individual who suffered from the violence (Jeong, 2018), however, the \#MeToo movement has led the public to recognise sexual violence as a social issue that society as a whole must contemplate together. In particular, the number of articles about problems in the current legal system and the social structures responsible for dealing with sexual violence have increased significantly since the \#MeToo movement began. There have also been increases in articles representing the victim's point of view, including her legal strategies and psychological status, as well as the voice of women as a community.

The present study does have some limitations. The first is the timing of the data collection and analysis. In particular, the case of Ahn Hee-jung's sexual assault was a long-running case when the data were collected for research. Thus, the number of articles focusing on this case available for analysis in future studies may mean their results differ significantly from those of the present study. The frames, in particular, may be affected by changes in journalists' perspectives or by changes in society and public perception as time move forwards (Berkowitz, 1997).

In addition, this study produced results by analysing the contents of news articles on sexual violence, but the results of the study revealed only the status quo. Therefore, future research should include in-depth discussion using discourse analysis on how the stories in sexual assault articles are conceptualised. It should also be noted that reports of sexual assaults have been quantitatively as well as qualitatively transformed by the \#MeToo movement, as mentioned earlier. A longitudinal study on whether the quantitative changes in sexual assault news articles caused by the \#MeToo movement will continue or end up being fragmentary is also necessary.

\section{References}

Andelsman, V., \& Mitchelstein, E., 2019, If it Bleeds it Leads: Coverage of violence against women and sexual and reproductive health in Argentina from 1995 to 2015. Journalism Practice, 13(4), 458-475.

Berkowitz, Daniel, ed. 1997, Social Meanings of News: A Text-Reader. (Thousand Oaks, CA: Sage)

Entman, R. M. 1991. Framing U.S. Coverage of International News. Journal of Communication, 41(4), 6-27.

Flum, M., 2018, A year ago, Alyssa Milano started a conversation about \#MeToo. These women replied. NBC News, October 16.

Frye, J., 2018, From politics to policy: Turning the corner on sexual Harassment-Center for American Progress. Center for American Progress, January 31.

Gamson, W. A., \& Modigliani, A. 1989, Media Discourse and Public Opinion on Nuclear Power: A Constructionist Approach. American Journal of Sociology, 95(1), 1-37.

Gitlin, T., 1980, The Whole World is Watching: Mass Media in the Making and Unmaking of the New Left, Berkeley (CA: University of California Press).

Goffman, E., 1974, Frame Analysis: An Essay on the Organization of Experience. (Cambridge, MA: Harvard University Press). 
Gross, K., \& Brewer, P. R., 2007, Sore losers: News frames, policy debates, and emotions. Harvard International Journal of Press/Politics, 12(1), 122-133.

Hasunuma, L., \& Shin, K. Y., 2019, \# MeToo in Japan and South Korea:\# WeToo,\# WithYou. Journal of Women, Politics \& Policy, 40(1), 97-111.

Hindes, S., \& Fileborn, B., 2019, Girl power gone wrong:\# MeToo, Aziz Ansari, and media reporting of (grey area) sexual violence. Feminist Media Studies, 1-18

Hust, Stacey J.T., Emily Garrigues Marret, Chunbo Ren, Paula M. Adams, Jessica F. Willoughby, Lei Ming, Weina Ran, and Cassie Norman., 2014, Establishing and Adhering to Sexual Consent: The Association between Reading Magazines and College Students' Sexual Consent Negotiation. Journal of Sex Research, 51(3), 280290.

Hong, J. A., 2009, The constitution of meaning of sexual violence: Frame analysis of JoogAng Daily Newspaper and Hankyoreh, Korean Journal of Broadcasting and Telecommunication Studies, 23(5), 458-498.

Iyengar, S., \& Peters, M. D., \& Kinder, D. R., 1982, Experimental Demonstrations of the "Not-So-Minimal" Consequences of Television News Programs. American Political Science Review, 76, 848-858.

Iyengar, S., \& Simon, A., 1993, News coverage of the Gulf crisis and public opinion: A study of agenda-setting, priming, and framing. Communication research, 20(3), 365-383.

Jeong, H. J., 2018, Gender Society and \#MeToo, Munhakdongne, 25(2), 348-366. [In Korean]

Kim, H. M., 2018, Me Too Movement, Why, Now and After, Gender Review, 49, 4-13. [In Korean]

Kim, J. S., 2018, After the disclosures: a year of \# sexual_violence_in_the_film_industry in South Korea. Feminist Media Studies, 18(3), 505-508.

Kim, L., 2011, Media framing of stem cell research: A cross-national analysis of political representation of science between the UK and South Korea. Journal of Science Communication, 10(3), 1-16.

Kim, S. N., 2002, An analysis of prostitution related TV news frame, Korean Journal of Broadcasting and Telecommunication, 16(2), 41-76. [In Korean]

Kim, S. N. and Jang, H. S., 2011, A study on the characteristic features shown by Korean newspapers in reporting sexual violence. Journal of Political Communication, 22, 5-36. [In Korean]

Kim Y. H., 2002, Fundamental Understanding of the Media Reform, Politics on the Film Source Book: Political Power and Media Power 10. (Seoul: Press Reform Civil Solidarity) [In Korean]

Kim Y. K, Kim J. H., and Kim, Y. S., 2013, A study on sexual violence news frame in personal perception: The mediation effect of discrete emotion, Korean Journal of Journalims \& Communication Studies, 57(1), 245-271. [In Korean]

Kosicki, G. M., 1993, Problems and Opportunities in Agenda-Setting Research. Journal of Communication, 43(2), 100-127.

Lee, H. C., Gross, M. J., \& Lee, S. H., 2010, A Comparison of Reporting Tendency Between Conservative and Progressive Korean Newspapers Towards Travel to Australia. In New Zealand Tourism and Hospitality Research Conference, 2010, 51-68.

Price, V., \& Tewksbury, D., \& Powers, E., 1997, Switching Trains of Thought. Communication Research, 24(5), 481-506.

Ryall, J., 2018, South Korean actor's suicide triggers backlash against \#MeToo. The Telegraph, March 12.

Scheufele, D. A., 1999, Framing as a Theory of Media Effects. International Communication Association, 49(1), 100-122.

Shen, F., 2004, Effects of news frames and schemas on individuals' issue interpretations and attitudes. Journalism \& Mass Communication Quarterly, 81(2), 400-416.

Tuchmann. G.,1978. Making News: A Study in the Construction of Reality (New York: the Free Press)

Yang, J. H., 2001, Media framing of a social conflict: (a) case study of medical doctors' strike in Korea, Korean journal of journalism \& communication studies, 45(2), 284-31. [In Korean] 